\title{
Dimensional Changes and Microstructural Evolution in a B-bearing Steel in the Simulated Forming and Quenching Process
}

\author{
Mahesh C. SOMANI, L. Pentti KARJALAINEN, Magnus ERIKSSON"1) and Mats OLDENBURG ${ }^{11}$ \\ University of Oulu, Department of Mechanical Engineering, Box 4200, FIN-90014 Oulun Yliopisto, Finland. \\ E-mail: pentti.karjalainen@oulu.fi $\quad$ 1) Luleå University of Technology, Department of Mechanical Engineering, S-971 87 \\ Luleå, Sweden.
}

(Received on October 23, 2000; accepted in final form on January 22, 2001)

\begin{abstract}
To improve the modelling of the behaviour of steel profiles in the forming and quenching process, the influences of high-temperature plastic deformation and applied stress on the martensitic transformation were investigated in a B-bearing steel by dilatometric measurements and compression tests. The plastic deformation of austenite was found to enhance ferrite formation so significantly that the dilatation due to the low-temperature transformation decreases even at a cooling rate of $280^{\circ} \mathrm{C} / \mathrm{s}$. The presence of ferrite in the microstructure results in markedly lower hardness and flow stress than the completely martensitic microstructure. Possibilities to avoid ferrite formation have been discussed. Stress applied during the martensitic transformation increases diametric dilatation by as much as $200 \%$ under axial compression, which seems to result from the preferred orientation of the martensite formed. However, subsequent to a hightemperature plastic deformation, the influence of applied stress remains much smaller.
\end{abstract}

KEY WORDS: dilatation; boron-bearing steel; martensitic transformation; forming; cooling; plastic deformation; strain-induced ferrite; transformation plasticity.

\section{Introduction}

Modelling and simulation are gaining increasing importance in the product development of structural components whose manufacturing is based on thermomechanical forming. However, finite element simulations of coupled thermomechanical processes require accurate and efficient simulation tools as well as relevant material data based on testing of the mechanical and thermal properties under reliably simulated processing conditions.

Simultaneous forming and quenching is a patented manufacturing process for high-strength steel sheets and profiles with a closed cross-section, which are used in safetyrelated structural components in car body structures for weight reduction, good structural stiffness and strength and enhanced safety. ${ }^{1,2)}$ In the process, thin-walled profiles or blanks of hardenable steel are heated to the austenite region, placed in a cooled forming tool, where they are simultaneously formed to the desired shape and hardened, or alternatively, clamped, formed and subsequently hardened by spray-quenching, and released. The final mechanical properties depend on the microstructural evolution.

The model requirements for the forming and quenching process have been described in detail by Bergman ${ }^{1)}$ and Eriksson. ${ }^{2)}$ The material model that can be used for the coupled thermo-elasto-plastic analyses is based on the "effective-stress" function and incorporates a temperature-depen- dent non-linear hardening rule and modelling of transformation plasticity. The volume changes during the martensitic transformation are expressed as the thermal expansion function defined for the material. In addition, a specific phenomenon called transformation plasticity may be present due to internal stresses in the formed and cooled components. The contraction and volume change due to martensite formation together with the transformation plasticity strain are to be accounted for as a driving force for the thermal stresses and dimensional stability of the component.

This work is part of the research project titled Low Weight High Performance Steel Structures (LOWHIPS) underway at Luleå University of Technology, Sweden in cooperation with the University of Oulu, which aims to improve the modelling of the forming and quenching process and to determine the data for relevant mechanical properties by physical simulation testing. Compression tests under fast cooling have been used to simulate the process. A detailed measurements of the flow stresses for austenitic, completely martensitic or mixed austenite + martensite + bainite microstructures will be reported elsewhere. ${ }^{3)}$ In principle, plastic working may enhance martensite formation or stabilize austenite (see the discussions in Refs. 1) and 2)). To investigate the situation in the present steel, dilatometric recordings were used to clarify the effects of high-temperature plastic deformation at the austenite phase on the subse- 
quent phase transformations. The microstructural evolution has also been examined briefly. If a transformation takes place under an external or internal stress, extra transformation plasticity strain may occur. ${ }^{4)}$ Therefore, the influence of applied stress, simulating the presence of residual stresses in a formed component, on the dimensional changes occurring during the martensitic transformation has finally been studied.

\section{Experimental Procedure}

The material used in the tests is a boron-bearing steel, Boloc $^{\circledR}$ 02, also called Docol, with the following chemical composition (wt \%): $0.22 \mathrm{C}-0.29 \mathrm{Si}-1.1 \mathrm{Mn}-0.013 \mathrm{P}-0.003 \mathrm{~S}-$ $0.21 \mathrm{Cr}-0.0034 \mathrm{~B}-0.05 \mathrm{Al}-0.0025 \mathrm{~N}$. The material was supplied by SSAB Steel, Sweden, in the form of a $2000 \times$ $1000 \times 10 \mathrm{~mm}$ plate. A typical continuous cooling transformation diagram (CCT) as reported by the steel manufactur$\mathrm{er}^{5)}$ is shown in Fig. 1. As the figure indicates, a cooling rate higher than about $30^{\circ} \mathrm{C} / \mathrm{s}$ results in a completely martensitic structure. The hardened state gains a yield strength as high as 1200-1300 MPa with elongation around $10 \%$ at ambient temperatures.

A Gleeble 1500 thermomechanical simulator was employed in the study. Dilatometric measurements were carried out using cylindrical specimens of $4 \mathrm{~mm}$ dia $\times 5.5 \mathrm{~mm}$ (suitable for compression testing). In some cases, long rods of $10 \mathrm{~mm}$ dia with a reduced middle gauge section of $4 \mathrm{~mm}$ dia $\times 5 \mathrm{~mm}$ were used (suitable for tensile straining). The specimens were first heated at $900^{\circ} \mathrm{C}$ for $5 \mathrm{~min}$. In some cases, reheating at $1000^{\circ} \mathrm{C}$ for 5 min was used to obtain a coarser austenite grain size. A controlled, linear cooling rate up to $150^{\circ} \mathrm{C} / \mathrm{s}$ or natural cooling at a rate of $280^{\circ} \mathrm{C} / \mathrm{s}$ (at about $600^{\circ} \mathrm{C}$ ) could be achieved using the latter geometry. The diametric (crosswise) dilatation was continuously recorded in all tests.

The forming and quenching process was simulated by hot compression and simultaneous or subsequent fast cooling. In order to reveal the effects of high-temperature plastic deformation on dimensional changes and microstructural evolution, in one series of tests, the specimens were subjected to a plastic strain up to 0.4 by applying a uniaxial compressive stress up to $340 \mathrm{MPa}$ at $700-800^{\circ} \mathrm{C}$ in the course of cooling at a rate of $50^{\circ} \mathrm{C} / \mathrm{s}$. In order to control the deformation temperature more strictly, in some tests loading took place isothermally at $750^{\circ} \mathrm{C}$, which stage was followed by linear cooling at various constant cooling rates within $50-150^{\circ} \mathrm{C} / \mathrm{s}$ or by natural cooling at a cooling rate about $280^{\circ} \mathrm{C} / \mathrm{s}$ around $600^{\circ} \mathrm{C}$. The load was removed before the temperature reached $600-550^{\circ} \mathrm{C}$, i.e. well before the onset of the martensitic transformation.

In addition to the above tests, a few experiments were carried out using continuous compression while the temperature of the specimen was decreasing. This simulated a longer forming stage under cooling, and the flow resistance (a force required for forming) was of the main interest. Compression was started at different temperatures ranging within $800-500^{\circ} \mathrm{C}$, and a low strain rate in the range of $0.04-0.08 \mathrm{~s}^{-1}$ was adopted, so that deformation could be continued down to a temperature of $350-200^{\circ} \mathrm{C}$, while a true strain of $0.5-0.9$ was reached.

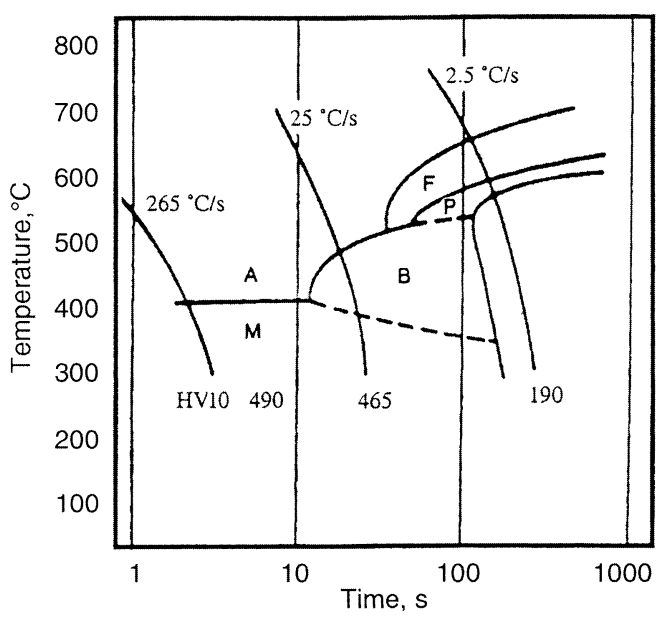

Fig. 1. CCT diagram of the steel tested. ${ }^{5}$

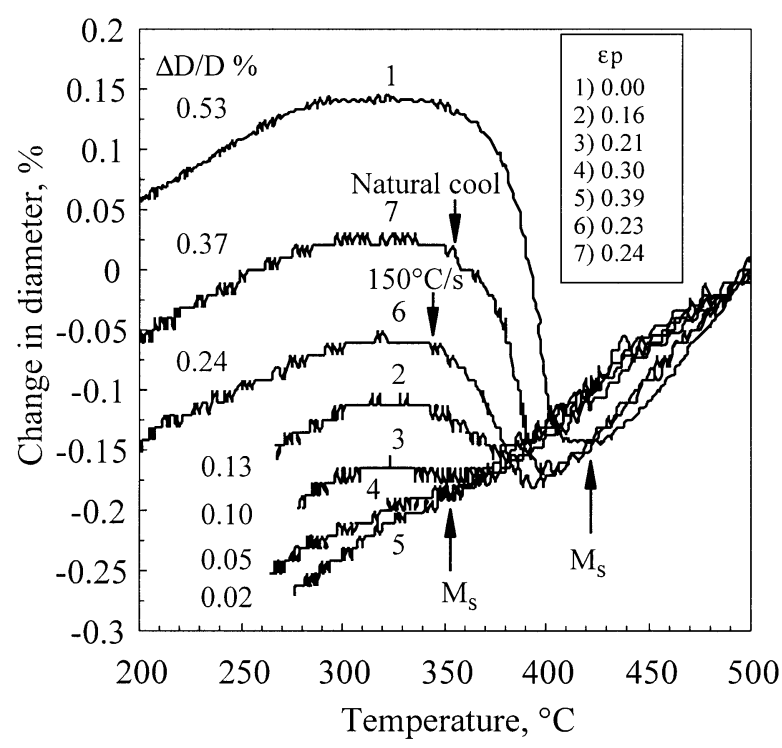

Fig. 2. Relative diametric changes of the specimens in the course of cooling and those in the martensitic transformation $(\Delta D / D)$ after plastic straining $\left(\varepsilon_{\mathrm{p}}\right)$ at high temperatures.

In order to investigate the transformation plasticity, the influence of residual or external stresses on dimensional changes during the martensitic transformation, a series of tests was carried out. In them, an axial compressive or tensile stress at 0-260 MPa, i.e. in the elastic range or causing a very small plastic strain, was quickly applied at about $600-500^{\circ} \mathrm{C}$ and maintained during the subsequent cooling of the specimens, which, in some tests, had been previously deformed at a higher temperature. The change in the diameter of the specimen was recorded continuously.

In a few cases, the microstructures of the specimens were examined under optical and scanning electron microscopes. A detailed investigation was not aimed, so that the distinction between the bainite and martensite phases, for instance, requiring the use of a transmission electron microscope, was not tried. Hardness, to obtain information on the type and strength of the microstructures, was determined using the Vickers method and the load of $10 \mathrm{~kg}$ (HV10). 


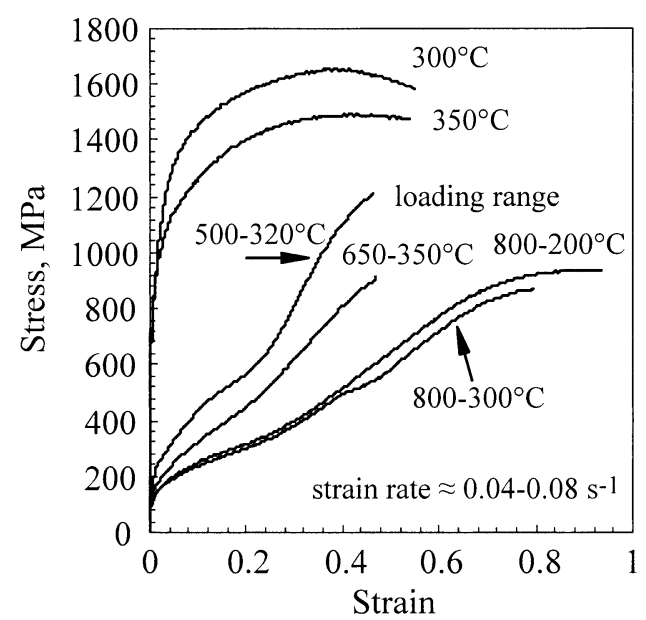

Fig. 3. Flow stress under continuous compression in various temperature regimes during cooling at $50^{\circ} \mathrm{C} / \mathrm{s}$ or in isothermal tests at $300^{\circ} \mathrm{C}$ and $350^{\circ} \mathrm{C}$.

\section{Results}

\subsection{Dilatation after High-temperature Plastic De- formation}

Figure 2 shows the relative change in the specimen diameter (dilatation) at temperatures below $500^{\circ} \mathrm{C}$ in the course of cooling from $900^{\circ} \mathrm{C}$ following different plastic strains applied under continuous cooling at $800-700^{\circ} \mathrm{C}$ or isothermally at $750^{\circ} \mathrm{C}$. It can be seen that, without plastic deformation (curve 1), austenite starts to decompose into martensite at $425^{\circ} \mathrm{C}\left(\mathrm{M}_{\mathrm{s}}\right)$, and the constant new slope appears at around $280^{\circ} \mathrm{C}\left(\mathrm{M}_{\mathrm{f}}\right)$. The relative change in diameter in the martensitic transformation $(\Delta D / D)$ was measured as a difference between the contraction lines for austenite (the high-temperature part) and martensite (the low-temperature part) as extrapolated to the mean temperature between $\mathrm{M}_{\mathrm{s}}$ and $\mathrm{M}_{\mathrm{f}}$. At that point it is about $0.53 \%$. It appears obvious that, at a cooling rate of $50^{\circ} \mathrm{C} / \mathrm{s}$ (curves $1-5$ ), $\Delta D / D$ decreases drastically with increasing prior plastic strain and $\mathrm{M}_{\mathrm{s}}$ also distinctly decreases. The effect is very pronounced, as $\Delta D / D$ is only $0.13 \%$ even with a plastic strain of 0.16 (curve 2), and following the strain 0.39 (curve 5), there is hardly any extra dilatation visible below $\mathrm{M}_{\mathrm{s}}$.

A couple of the curves (curves 6 and 7) shown in the figure have also been drawn from the tests, in which a plastic strain of $0.23-0.24$ was applied at $750^{\circ} \mathrm{C}$, followed by cooling at a rate of $150^{\circ} \mathrm{C} / \mathrm{s}$ or under natural cooling, i.e. about $280^{\circ} \mathrm{C} / \mathrm{s}$ at $600^{\circ} \mathrm{C}$. It is obvious that $\Delta D / D$ in these instances is much greater than at a cooling rate of $50^{\circ} \mathrm{C} / \mathrm{s}$ at a corresponding strain (curves 3 and 4), but still less than without any plastic strain (curve 1).

Hence, the reduced diametric change in the martensitic transformation observed seems to indicate that less martensite is formed at low temperatures if the specimen is deformed at a high temperature, which must be due either to the stabilisation of austenite or to the formation of ferrite and/or bainite before cooling to $\mathrm{M}_{\mathrm{s}}$. The latter phenomenon seems to occur, and it will be discussed later.

\subsection{Deformation under Continuous Cooling}

Typical stress-strain curves obtained while the specimens were compressed during cooling at $50^{\circ} \mathrm{C} / \mathrm{s}$ are shown

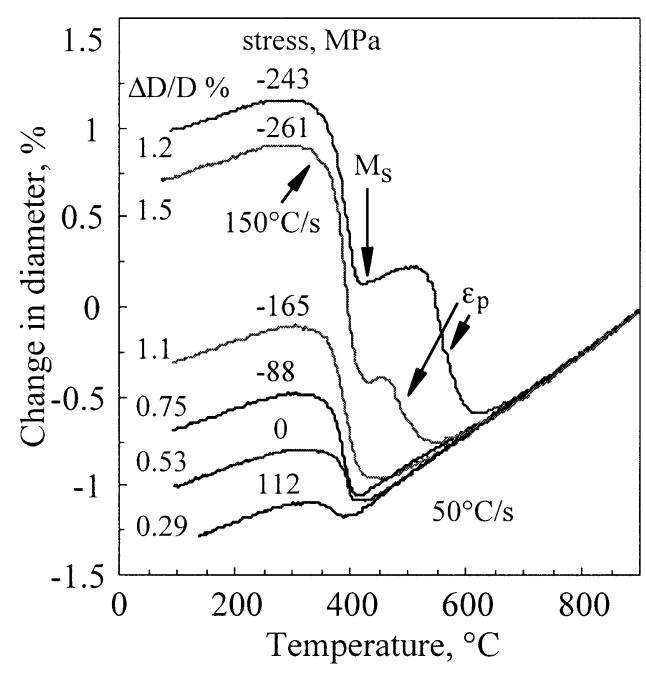

Fig. 4. Relative diametric changes of the specimens in the course of cooling and those in the martensitic transformation $(\Delta D / D)$ under applied stress. At the two highest stresses, minor plastic yielding $\left(\varepsilon_{\mathrm{p}}\right)$ occurs before the transformation.

in Fig. 3. The deformation was started at different temperatures, 800,650 or $500^{\circ} \mathrm{C}$, i.e. above, near or below $\mathrm{A}_{\mathrm{r} 3}$ $\left(\approx 680^{\circ} \mathrm{C}\right.$ at $\left.10^{\circ} \mathrm{C} / \mathrm{s}\right)$. Flow resistance increased with increasing strain and decreasing temperature, but the different strain rates used $\left(0.04-0.08 \mathrm{~s}^{-1}\right)$ had no distinct influence. However, the final flow stress level reached at the strain of 0.8 is only about $900 \mathrm{MPa}$ at the final temperature of $300^{\circ} \mathrm{C}$, when compression was started at $800^{\circ} \mathrm{C}$. This level is evidently much lower than that obtained for a cooled structure isothermally deformed, which is around 1450$1600 \mathrm{MPa}$. In cases with lower-temperature deformation, especially when starting at $500^{\circ} \mathrm{C}$, the flow stress rises higher, but it still seems to remain lower than under isothermal compression.

\subsection{Influence of Applied Stress on Dilatation}

A number of dilatometric measurements on specimens under stress (elastic strain) were carried out to simulate the influence of residual stresses on the $\mathrm{M}_{\mathrm{s}}$ temperature and the relative change in diameter $(\Delta D / D)$ in the martensitic transformation. Typical dilatometric curves are displayed in Fig. 4. As seen in the figure, an increase of compressive stress from 0 to $165 \mathrm{MPa}$ resulted in an increase in $\Delta D / D$ from $0.53 \%$ to $1.1 \%$. Even the value of $1.5 \%$ was measured at a stress of about $261 \mathrm{MPa}$, which slightly exceeds the yield strength, as shown by the small plastic strain $\left(\varepsilon_{\mathrm{p}}\right)$ seen in the dilatometric curves (at the stresses 243 and $261 \mathrm{MPa}$ ) before the start of the martensitic reaction.

Figure 5 shows the dilatation $\Delta D / D$ in the martensitic transformation as a function of compressive and tensile stress $(\sigma)$. Without any prior deformation of austenite, a linear relationship can be found for the stresses in the range $-165<\sigma<112 \mathrm{MPa}$ used in the experiments as follows:

$$
\Delta D / D(\%)=-0.0028 \sigma(\mathrm{MPa})+0.567 .
$$

with the correlation factor ( $R$-squared value) $R^{2}=0.97$. Higher compressive stresses, leading to a minor plastic strain of about $1 \%$, have resulted in even slightly higher dilatation than predicted from this equation. These results are 


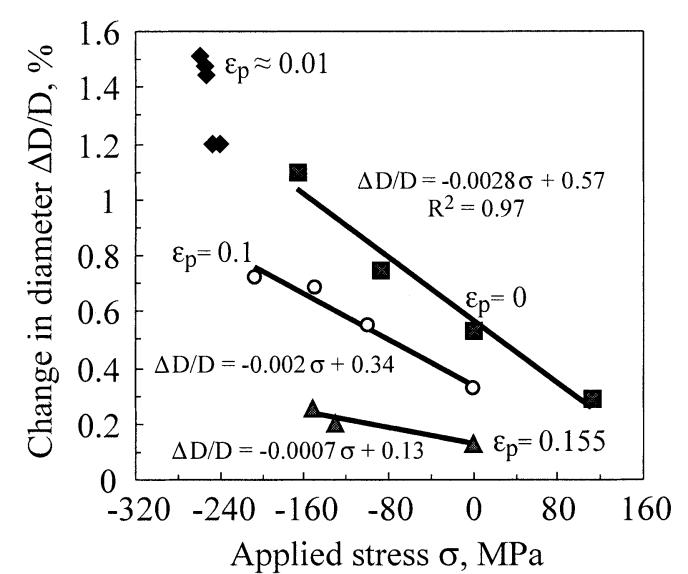

Fig. 5. Relationships between the applied stress $(\sigma)$ and the relative change in the diameter in the martensitic transformation $(\Delta D / D)$ at various prior plastic strains. The equations for the trend lines are shown.

in qualitative agreement with the earlier observations that a tensile stress increases the dilatation in the martensitic transformation measured in the longitudinal direction and a compressive stress decreases it. ${ }^{4}$ Here, the diametric strain was recorded, and the opposite direction of the change in the dilatation was therefore noticed. However, accounting for this, even the power of the stress, assuming that the diametric dilatation is half of the longitudinal, is almost the same $5.2 \cdot 10^{-5} / \mathrm{MPa}$ as determined by Denis et al. $^{4)}$ for a tool steel (60 NCD 11).

Compressive stresses also increase $\Delta D / D$ in the course of martensitic transformation from deformed austenite, as shown by the data in Fig. 5. After plastic strains of 0.1 and 0.155 at a temperature of $700-800^{\circ} \mathrm{C}$, linear relationships seem to be valid between the dilatation and compressive stresses. However, the dilatation and the slope are much smaller than in the case of undeformed austenite.

It can be seen from Fig. 4 that the $M_{s}$ temperature is hardly affected by these applied stresses within the accuracy of the measurements. It has been reported that both compressive and tensile stresses raise $\mathrm{M}_{\mathrm{s}}$, but the effect is small (for a review, see Ref. 6)). Denis et $a .^{4)}$ found an increase of $18^{\circ} \mathrm{C}$ in a tool steel at tensile stresses close to its yield strength of $285 \mathrm{MPa}$.

\section{Discussion}

\subsection{Austenite Decomposition Structures}

In order to achieve the target of weight reduction and high strength in the forming and quenching process, a hardenable steel has to be used. The present steel with (elements in $\mathrm{wt} \%$ ) $0.22 \% \mathrm{C}, 1.1 \% \mathrm{Mn}, 0.2 \% \mathrm{Cr}$ and $34 \mathrm{ppm} \mathrm{B}$ has been specifically developed to be used in hardened components. It has relatively high hardenablity, providing a completely martensitic structure after austenitisation at $900^{\circ} \mathrm{C}$ at cooling rates higher than $30^{\circ} \mathrm{C} / \mathrm{s}$, as concluded from Fig. 1. However, it appeared in the present tests that, following a plastic deformation of austenite, dilatation at low temperatures decreased and the flow stress under continuous compression remained at a much lower level than for the undeformed austenite even at cooling rates $\geq 50{ }^{\circ} \mathrm{C} / \mathrm{s}$. Microstructural investigations revealed that the final mi-
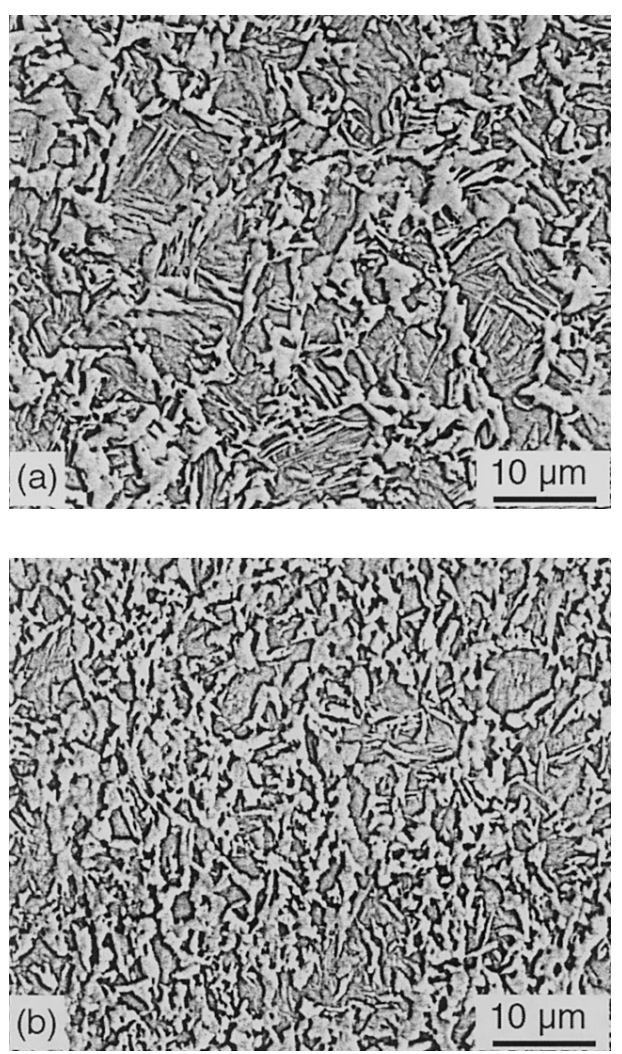

Fig. 6. Microstructures containing ferrite and martensite formed at a cooling rate of $50^{\circ} \mathrm{C} / \mathrm{s}$ after plastic strain of a) 0.16 , b) 0.39 .

crostructure consisted of at least two phases, presumably ferrite and martensite, the volume fractions of which varied, depending on the magnitude of the prior plastic strain and the cooling rate. As an example, the typical microstructures of specimens subjected to prior plastic strains of 0.16 (see curve 2 in Fig. 2) and 0.39 (curve 5 in Fig. 2) are displayed in Figs. 6(a) and 6(b), respectively. The lighter phase (ferrite) clearly outlines the darker areas (martensite and/or bainite), indicating the nucleation of ferrite on the austenite grain boundaries. The volume fractions of ferrite were estimated to be about 22 and $48 \%$ in the structures shown in Figs. 6(a) and 6(b), respectively.

In Fig. 2, small differences in the slopes of the dilatometric curves above $M_{s}$ can be noticed. The slope for undeformed austenite (curve 1 ) is about $2.3 \cdot 10^{-5} /{ }^{\circ} \mathrm{C}$ and that for martensite (curve 1 at low temperatures) $10^{-5} /{ }^{\circ} \mathrm{C}$. At a cooling rate of $50^{\circ} \mathrm{C} / \mathrm{s}$ for plastically deformed austenite and its high-temperature decomposition products (curves $1-5)$, the slope is $1.36 \cdot 10^{-5} /{ }^{\circ} \mathrm{C}$, while at a cooling rate of $150^{\circ} \mathrm{C} / \mathrm{s}$ (curve 6) or under natural cooling (curve 7), it is about $1.8 \cdot 10^{-5} /{ }^{\circ} \mathrm{C}$. However, the thermal contraction coefficient for ferrite measured at a cooling rate of $1{ }^{\circ} \mathrm{C} / \mathrm{s}$ was as high as $1.5 \cdot 10^{-5} /{ }^{\circ} \mathrm{C}$. This indicates that the slopes are too inaccurate to be used to calculate the ferrite fraction.

Furthermore, the $\mathrm{M}_{\mathrm{s}}$ temperature is lowered by about $25-70^{\circ} \mathrm{C}$ with increasing plastic strain from 0.16 to 0.39 . The reason for this might be that, as a consequence of ferrite formation, carbon becomes enriched in the remaining austenite, which therefore transforms into martensite at a somewhat lower temperature. For carbon, a coefficient of 350 is given in a regression equation to reduce $\mathrm{M}_{\mathrm{s}}{ }^{7)}$ Hence, 


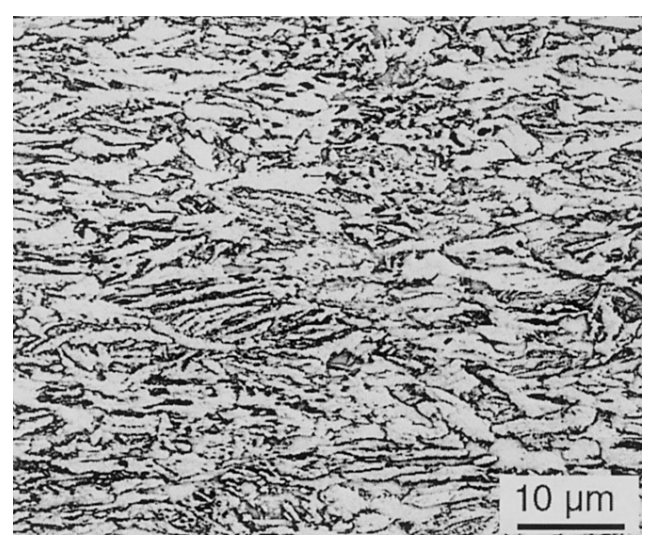

Fig. 7. Microstructure consisting of proeutectoid ferrite and ferrite-carbide aggregates formed during continuous compression at $0.08 \mathrm{~s}^{-1}$ and cooling at $50^{\circ} \mathrm{C} / \mathrm{s}$ from $800^{\circ} \mathrm{C}$ to $300^{\circ} \mathrm{C}$.

if $22 \%$ ferrite is present, the carbon content in austenite would be about $0.28 \%$ in the present steel, and correspondingly, $\mathrm{M}_{\mathrm{s}}$ would be lowered by $21^{\circ} \mathrm{C}$. A ferrite fraction of $50 \%$ would mean a $77^{\circ} \mathrm{C}$ reduction in $\mathrm{M}_{\mathrm{s}}$. These values are in reasonable agreement with the observations.

Marked acceleration of ferrite formation, and particularly the nucleation rate, by plastic deformation in the non-recrystallization regime of austenite has been reported for microalloyed steels. ${ }^{8)}$ Lee and $\mathrm{Choo}^{9)}$ found that pancaking of austenite by rolling at $871-843^{\circ} \mathrm{C}$ resulted in the appearance of ferrite in the course of subsequent quenching, i.e. a reduced hardenablity, in low-carbon B-bearing highstrength steels whose "alloy-determined" hardenability was relatively low (steel grades with $8-18 \mathrm{ppm}$ of boron). Without rolling, the microstructures were martensitic. It has also been observed that ferrite with an ultra-fine grain size can be formed as strain-induced by subjecting austenite to severe plastic straining at temperatures slightly above $\mathrm{A}_{\mathrm{r} 3} \cdot{ }^{10,11)}$

Under continuous deformation during cooling, starting at $800^{\circ} \mathrm{C}$, the strain reached about 0.4 at $600^{\circ} \mathrm{C}$ in the ferriteforming regime (within $4 \mathrm{~s}$ ) and 0.8 at $300^{\circ} \mathrm{C}$. The final microstructure seemed to consist of a mixture of proeutectoid ferrite (white grains) and another phase of ferrite with carbides, as displayed in Fig. 7. In consistence, the absence of any significant martensite formation was also supported by the observation that the cooling rate remained constant down to $200^{\circ} \mathrm{C}$, contrary to the case where the cooling of austenite took place without prior deformation, while the cooling rate decreased significantly as a temperature of about $400^{\circ} \mathrm{C}$ was reached, obviously due to the thermal dissipation effects of martensite formation.

Ferrite is a much softer phase than martensite. It is given a value of $180 \mathrm{HV}$ in the technical data, ${ }^{5)}$ and $170 \mathrm{HV} 10$ was measured for the specimen cooled at $1^{\circ} \mathrm{C} / \mathrm{s}$. Hardness measurements also confirmed that the microstructure formed after a high-temperature plastic deformation was remarkably softer, 302-440 HV10, while the martensite had a hardness of 490-510 HV10. Assuming that only ferrite and martensite are present, the mixture rule would suggest the following relationship for the hardness

$$
\mathrm{HV}=-335 f_{\alpha}+505
$$

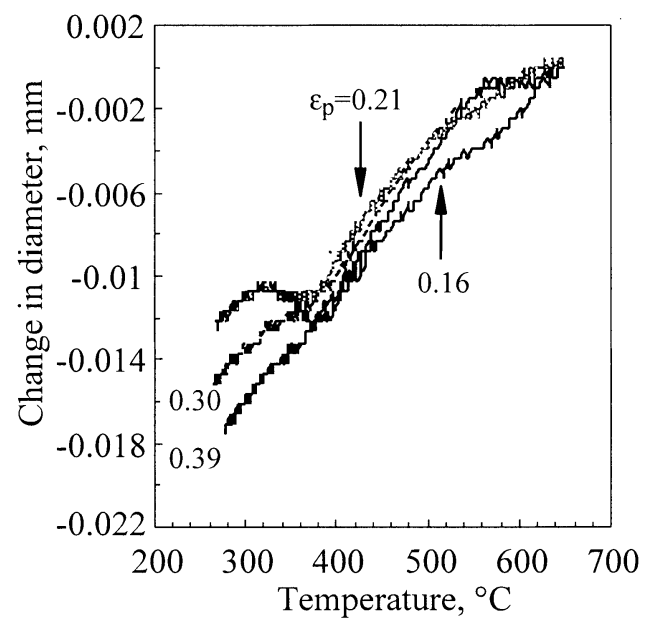

Fig. 8. Relative diametric changes below $700^{\circ} \mathrm{C}$ after different plastic strains at around $800^{\circ} \mathrm{C}$ and cooling at $50^{\circ} \mathrm{C} / \mathrm{s}$.

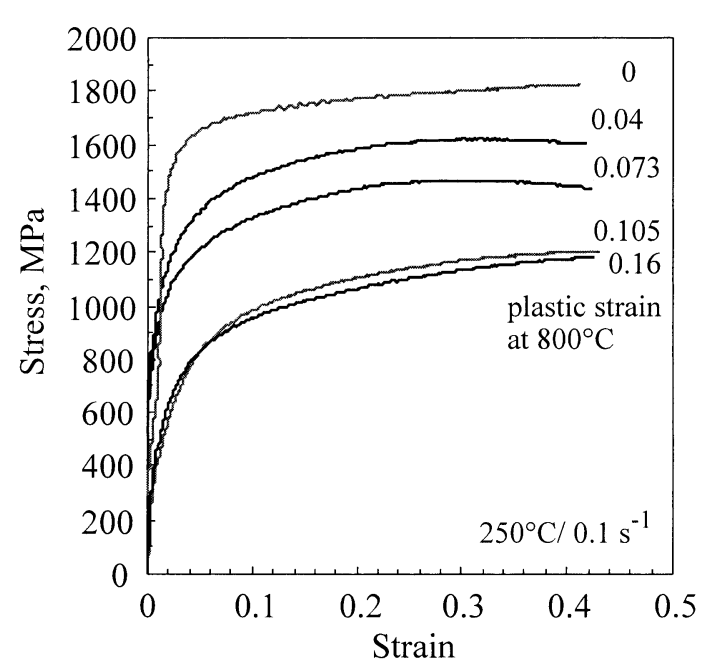

Fig. 9. Effect of prior plastic straining at $800^{\circ} \mathrm{C}$ on the flow stress curves at $250^{\circ} \mathrm{C}$, cooled at $50^{\circ} \mathrm{C} / \mathrm{s}$.

where $f_{\alpha}$ is the fraction of ferrite. However, if the ferrite fraction for the microstructures shown in Figs. 6(a) and $6(\mathrm{~b})$ is predicted on the basis of their measured hardness values, 345 and $302 \mathrm{HV} 10$, respectively, Eq. (2) gives $48 \%$ and $61 \%$, respectively, which values are considerably higher than the fractions determined metallographically. This may suggest that some bainite is present among the martensite. In fact, if the hardness of bainite is $\geq 400 \mathrm{HV} 10$, practically all of the second phase in addition to ferrite may be bainite rather than martensite. The distinction between the bainite and martensite phases might require transmission electron microscopic examinations, which have, however, not been performed, because this matter is not very important.

A careful analysis of dilatometric curves also revealed that, following the plastic deformation, there was already significant dilatation at a higher temperature regime of $600-400^{\circ} \mathrm{C}$, i.e. well above $\mathrm{M}_{\mathrm{s}}$. Some typical curves are shown in Fig. 8. It is evident that, with increasing plastic strain, the dilatation at higher temperatures increases, while the dilatation below $400^{\circ} \mathrm{C}$ decreases. The temperature regime of $400-550^{\circ} \mathrm{C}$ obviously corresponds to the range of bainite formation (Fig. 1). 


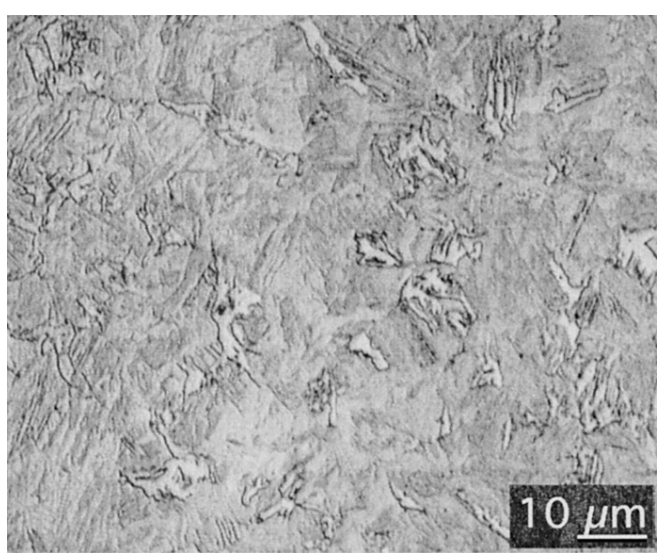

Fig. 10. Ferrite (about $6 \%$ ) among martensite after the plastic strain of 0.04 at $800^{\circ} \mathrm{C}$ and cooling at $50^{\circ} \mathrm{C} / \mathrm{s}$.

\subsection{Strength Properties Achievable}

The presence of ferrite would evidently mean poorer strength properties of the steel achieved. To have an estimate of this, the flow resistance of the final microstructure, after different plastic strains at $800^{\circ} \mathrm{C}$ and under continuous cooling at $50^{\circ} \mathrm{C} / \mathrm{s}$, was determined by compression testing at $250^{\circ} \mathrm{C}$. Typical flow stress curves are plotted in Fig. 9. A decreasing level of flow stress with an increasing prior plastic strain is evident, as shown by the marked drop at a strain as small as 0.04 . The corresponding microstructure after the test is shown in Fig. 10 revealing a few ferrite grains among martensite, the fraction about $6 \%$. After the strain of $0.04, \Delta D / D$ was about $0.4 \%$, which value is smaller than that $(0.53 \%)$ without any plastic deformation. All this is in agreement with the observations of microstructures. Especially the flow stress at small strains is significantly affected, obviously due to yielding of the softer ferrite $(170-180$ HV10) first. The similar trend in yield strength was very clear as a result of the changes in microstructure from hard martensitic to softer austenitic + bainitic or to austenitic, as reported in a previous paper. ${ }^{3)}$

Consequently, owing to the ferrite formation, the forming forces may remain low even at ambient temperatures, when the forming begins at a high temperature, but the high potential strength of a martensitic steel is not fully achieved, either. Therefore, several variables, such as the temperature at the moment of deformation, the amount of plastic strain and the cooling rate, are of importance and need to be optimised and controlled. In the present tests, even a cooling rate as high as $280^{\circ} \mathrm{C} / \mathrm{s}$ was unable to prevent a tiny fraction of ferrite to be formed, though only after the relatively high strain of 0.24 . It can be estimated that, in the practical forming process, the strain in a thin-walled profile (thickness $1-1.5 \mathrm{~mm}$ ) remains below 0.2 , which still highly exceeds the strain seen to reduce the flow stress in Fig. 9. In the hot stamping process, cooling is mainly caused by the contacts between the heated workpiece and the cold tools and naturally depends on the thickness of the sheet. Typical cooling rates of the order of $100^{\circ} \mathrm{C} / \mathrm{s}$ have been estimated by Bergman. ${ }^{1)}$ This is lower than the maximum rate of $280^{\circ} \mathrm{C} / \mathrm{s}$ used in the tests, still resulting in the formation of some ferrite. Hence, cooling rates high enough to avoid any ferrite formation at the most highly strained locations may be difficult to achieve.
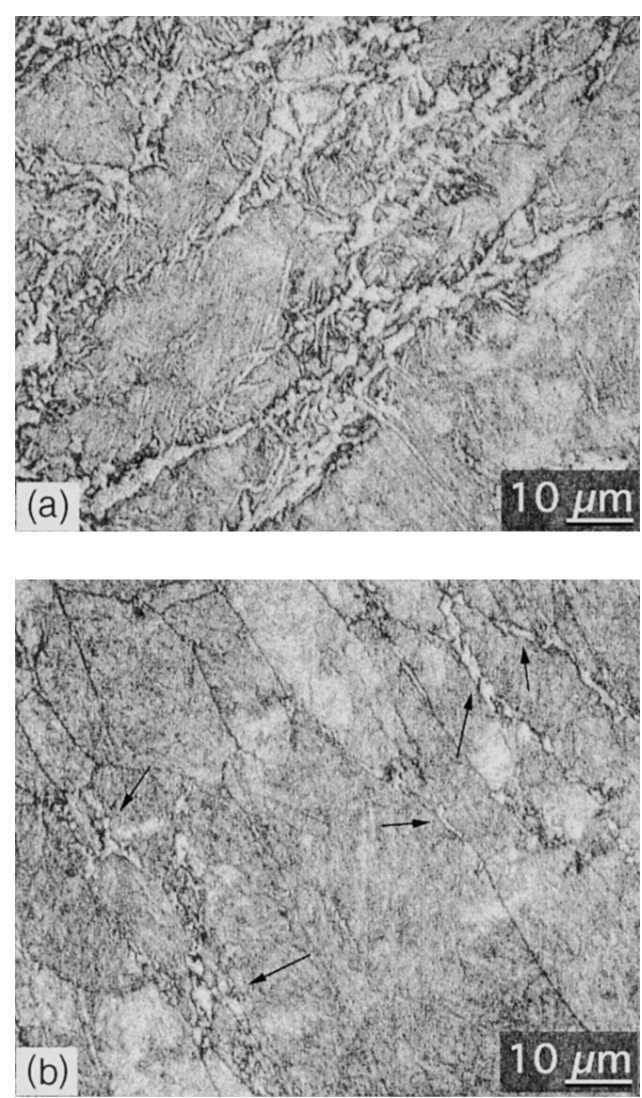

Fig. 11. Ferrite among martensite after the schedules: reheating at $1000^{\circ} \mathrm{C}$ for $5 \mathrm{~min}$, strain 0.24 at $750^{\circ} \mathrm{C}$ and cooling at a) $50^{\circ} \mathrm{C} / \mathrm{s}$, b) $150^{\circ} \mathrm{C} / \mathrm{s}$ (ferrite grains shown by arrows).

To avoid the strain-induced phase transformation, the consequences of the prior plastic deformation should be small enough or disappear before the temperature reaches the ferrite regime level. This means that forming should take place at a high temperature, $\geq 800^{\circ} \mathrm{C}$, where the driving force for the austenite decomposition is low, or the time should be long enough for static recrystallisation to occur. Recently, Yada et al. ${ }^{12)}$ showed that austenite can transform into ferrite due to plastic deformation even above the equilibrium start temperatures of proeutectoid ferrite, $\mathrm{A}_{3}$. For the present steel, $\mathrm{A}_{3}$ is about $780^{\circ} \mathrm{C}$ according to the dilatometric measurements. A rough estimate based on the recrystallisation kinetics of a low-carbon steel suggests that the time needed for complete recrystallisation would be about $29 \mathrm{~s}$ at $900^{\circ} \mathrm{C}$ (at a strain of 0.15 and a strain rate of $0.1 \mathrm{~s}^{-1}$ ) and $255 \mathrm{~s}$ at $800^{\circ} \mathrm{C} .{ }^{13)}$ Such long times are certainly not available due to the rapid cooling at least at the contact points of the profile and the tools. Another, more realistic alternative might be forming at low temperatures, such as $\leq 600^{\circ} \mathrm{C}$, i.e. below the ferrite regime. In that case, ferrite nucleation is not accelerated, although some enhancement of bainite formation may occur. This may not be so detrimental, however, due to the notably smaller strength difference between martensite and bainite. In order to avoid straining to continue at the martensitic stage, which would mean excessive forming loads, a major spring back and high residual stresses, forming should be finished above $420^{\circ} \mathrm{C}$, which means that the proper temperature range is quite narrow.

There are also factors which slow down diffusional trans- 
formations. The austenite grain size has an influence on its decomposition kinetics, and a higher austenitization temperature was therefore used in the experiment in order to delay the ferrite reaction. Indeed, the results indicated a higher dilatation $\Delta D / D \approx 0.24 \%$ in the case of reheating at $1000^{\circ} \mathrm{C}$ for $5 \mathrm{~min}$ (plastic straining to 0.24 and cooling at $50^{\circ} \mathrm{C} / \mathrm{s}$ ), compared to $0.04 \%$ after reheating at $900^{\circ} \mathrm{C}$ for $5 \mathrm{~min}$. The grain sizes were found to be $30 \mu \mathrm{m}$ and $10 \mu \mathrm{m}$ and the ferrite fractions about $6 \%$ and $35 \%$, respectively. At the higher cooling rate of $150^{\circ} \mathrm{C} / \mathrm{s}$, the respective dilatation values were $0.39 \%$ and $0.24 \%$, while the ferrite fractions were $2 \%$ and $6 \%$. Figure 11 shows the microstructures of the coarser-grained steel at two cooling rates, $50^{\circ} \mathrm{C} / \mathrm{s}$ (Fig. $11(\mathrm{a})$ ) and $150^{\circ} \mathrm{C} / \mathrm{s}$ (Fig. $11(\mathrm{~b})$ ). Hence, the high reheating temperature of $1000^{\circ} \mathrm{C}$ reduces considerably the amount of ferrite transformation, but fails to completely eliminate it.

\subsection{Transformation Plasticity Strain}

When transformation takes place under stress, transformation-induced plasticity occurs relative the applied stress and the progress of transformation. ${ }^{4)}$ Magee $^{14)}$ has proposed that, in the case of a martensitic reaction, the preferential orientation of martensite and the internal stress accommodation may contribute to transformation plasticity. In consistence with these observations, the stress applied in the present tests affected the degree of diametric strain, and compressive stress increased it by as much as $200 \%$. The longitudinal strain was also recorded in most cases, although it was not straightforward and accurate. The longitudinal change was opposite to the diametric change, i.e. a greater change in diameter corresponded to a smaller change in the longitudinal direction. This is in agreement with the Magee ${ }^{14)}$ mechanism. It can be assumed that the transverse tensile elastic strain due to axial compressive stress aids the formation of martensite, as its long $c$-axis of the tetragonal lattice tends to align in the transverse direction, i.e., the direction of tensile strain. The special texture of martensite formed under an elastic strain field was also confirmed by measuring the orientation distribution function (ODF) by X-ray diffraction. This indicates that residual stresses may significantly affect the dimensional changes resulting from the martensitic transformation, and these changes seem to have peculiar directionality. However, it should be noticed that, after plastic straining at a high temperature, the influence of the applied stress was much smaller in the present steel. This can simply be explained as a result of the lower fraction of martensite due to strain-induced ferrite formation.

\section{Conclusions}

The influences of plastic deformation and applied stress on the decomposition of austenite and dimensional changes in a B-bearing steel have been investigated by dilatometric measurements, compression testing and metallography. The following conclusions can be drawn:

Plastic straining at high temperatures of $700-800^{\circ} \mathrm{C}$ results in a significantly reduced relative diametric change during the martensitic transformation at $350-400^{\circ} \mathrm{C}$. This is a result of the prior strain-induced ferrite formation and, consequently, a reduced fraction of martensite in the final microstructure. At a cooling rate of $50^{\circ} \mathrm{C} / \mathrm{s}$, about 6,22 and $48 \%$ of ferrite is present after the strains of $0.04,0.16$ and 0.39 , respectively. A tiny fraction of ferrite is formed even at a cooling rate of $280^{\circ} \mathrm{C} / \mathrm{s}$ after a plastic strain of 0.24 .

Even a plastic strain as small as 0.04 (ferrite fraction about $6 \%$ ) is high enough to lead to a distinct reduction in the flow resistance at low temperatures as an indication of a softer microstructure. Continuous compression to strains of 0.4-0.8 during a continuous decline of temperature (at $\left.50^{\circ} \mathrm{C} / \mathrm{s}\right)$ results in much lower final flow stress levels $\left(800_{-}\right.$ $950 \mathrm{MPa}$ at $320-350^{\circ} \mathrm{C}$ ) than those obtained for a martensitic structure in isothermal tests $(1450-1600 \mathrm{MPa})$. A microstructure of fine-grained proeutectoid ferrite and ferritecarbide aggregates is formed under continuous deformation.

A linear relationship between the dilatation in the martensitic transformation and the applied stress in the elastic region or even slightly exceeding the yield strength was found. Diametric dilatation increases by almost $200 \%$ with increasing axial compressive stress. The axial tensile stress, on the other hand, has a reducing effect on diametric dilatation. Following the plastic deformation of austenite, the influence of the applied stress on dilatation remains much weaker due to the lower fraction of martensite in the microstructure.

It seems that martensite has formed in the preferred orientation under uniaxial stress (elastic strain).

Special caution is necessary to avoid excessive ferrite formation and to achieve the desired mechanical properties in formed and quenched components, when using the present steel grade. Minimisation of the plastic strain, maximisation of the cooling rate and/or forming at $600-450^{\circ} \mathrm{C}$ may be suitable ways to attain this. Austenitisation at high temperatures $\left(\geq 1000^{\circ} \mathrm{C}\right)$ seems also to give certain advantages.

\section{Acknowledgements}

Funding from the Swedish Foundation for Strategic Research and Volvo Car Corporation is gratefully acknowledged for the research project LOWHIPS.

\section{REFERENCES}

1) G. Bergman: Ph. D. Thesis, Luleå University of Technology, Luleå, (1999).

2) M. Eriksson: Lic. Thesis, Luleå University of Technology, Luleå, (2000).

3) M. Eriksson, M. Oldenburg, M. C. Somani and L. P. Karjalainen: "Material tests and evaluation of material parameters for analysis of forming and hardening of boron steel components", submitted to Mater. Sci. Eng.

4) S. Denis, A. Simon and G. Beck: Trans. Iron Steel Inst. Jpn., 22 (1982), 504.

5) DOCOL Teknikrapport MAS 5:1, SSAB Tunnplåt AB, Sweden, (1994).

6) S. Denis, E. Gautier, A. Simon and G. Beck: Mater. Sci. Technol., 1 (1985), 805 .

7) Werkstoffkunde Stahl, Band 1, VDE, Springer Verlag, Düsseldorf, (1984), 229.

8) I. Tamura, C. Ouchi, T. Tanaka and H. Sekine: Thermomechanical Processing of High Strength Low Alloy Steels, Butterworths, London, (1988), 99.

9) C.-S. Lee and W.-Y. Choo: ISIJ Int., 40 (2000), S189.

10) H. Mabuchi, T. Hasegawa and T. Ishikawa: ISIJ Int., 39 (1999), 477.

11) P. Hodgson, M. R. Hickson and R. K. Gibbs: Mater. Sci. Forum, 284-286 (1998), 63.

12) H. Yada, C.-M. Li and H. Yamagata: ISIJ Int., 40 (2000), 200.

13) L. P. Karjalainen and J. Perttula: ISIJ Int., 36 (1996), 729.

14) C. L. Magee: $\mathrm{Ph}$. D. Thesis, Carnegie Mellon Institute of Technology, Pittsburgh, PA, (1966). 